\title{
The Impact of Domestic Work on Men's and Women's Wages
}

Past research has consistently found that the negative relationship between housework and wages is stronger for women than for men. This article tests a potential explanation for this difference by focusing on the fact that men and women typically perform different types of household chores. Traditionally "feminine" and "masculine" task types are likely to interfere with work differently, because they vary as to when and how often they must be performed. Based on longitudinal data from the National Survey of Families and Households, fixed-effects regression results show that only time spent in female housework chores has a negative effect on wages. Furthermore, gender differences in the effect of housework disappear upon disaggregating housework into task types. This research suggests that a more equitable distribution of not only the amount, but also the type, of housework performed by men and women in the home may lead to a narrowing of the gender gap in wages.

Over the past few decades, there has been a dramatic increase in the percentage of married women participating in the labor force. Among married women with children younger than 6 years old, $64 \%$ worked outside the home in 1998, compared to only $19 \%$ in 1960 (U.S. Bureau of the Census,

Population Studies Center, University of Michigan, 426 Thompson Street, P.O. Box 1248, Ann Arbor, MI 481061248 (mnoonan@umich.edu).

Key Words: fixed-effects models, gender, housework, wage gap, work-family conflict.
1999). Despite these extensive changes in women's employment rates, housework has remained "women's work." Married women's movement into paid employment has not been accompanied by a significant increase in the amount of housework done by husbands, and thus responsibility for the "second shift" of housework has fallen primarily on working wives (Berk, 1985; Coverman \& Sheley, 1986; Hochschild, 1989; Kamo, 1988; Shelton, 1990).

Previous research has argued that household responsibilities may have a negative effect on wages, and thus that women's disproportionate responsibility for household work may be one factor contributing to the earnings gap between men and women. The hypothesized negative effect of housework on wages has generally been supported by past empirical research (Baxter, 1992; Coverman, 1983; Hersch, 1985, 1991a, 1991b; Hersch \& Stratton, 1997; McAllister, 1990; Shelton \& Firestone, 1988a). However, results consistently suggest that women incur a statistically significant greater penalty for housework time than do men. This raises an important question: Why does time spent on housework affect women's earnings more than men's?

Although some have speculated that the differential effects of housework time on earnings may be due to men and women performing different types of chores (Hersch, 1991a, 1991b), this hypothesis has not yet been tested empirically. Instead, past research has focused exclusively on the effect of the total number of hours of housework performed by husbands and wives, not the impor- 
tance of task-type distinctions. Distinguishing between task types is necessary and important because "female-type" tasks, unlike "male-type" tasks, generally need to be performed frequently and at specific times; performance of female tasks might thus have a more negative effect on wages than performance of male tasks. Attention to task type could also conceivably explain why past research has found gender differences in the effect of total housework time on wages. It may be that men and women are still performing different types of household tasks, and it is female tasks particularly that affect wages.

This article makes two contributions to research on the impact of housework on wages. First, I refine the arguments linking men's and women's involvement in domestic work to their wages by categorizing housework into different types of chores, asking whether this dimension of household work affects wages. Second, longitudinal panel data are used to formulate fixed-effects models, providing a clearer specification of the relationship between housework time and wages. By relying on cross-sectional data, previous studies (with the exception of Hersch \& Stratton, 1997) have been unable to control for unobserved heterogeneity, leading to potentially biased results.

\section{BACKGROUND}

Scholars have argued that domestic work may affect wages through the amount one is able to work, the type of job one chooses or is placed in, energy available for market work, and discrimination by employers. First, housework may affect wages by restricting the amount one is able to work. This argument rests on the notion that a trade-off between housework and paid labor is likely to exist, because time is a finite resource. In other words, housework responsibilities may cause one to reduce the number of work hours or leave the labor market altogether (Mincer \& Polachek, 1974). Individuals not working or working part-time will accumulate less work experience, compared to those employed continuously fulltime. According to human capital theory, experience is positively associated with earnings. Furthermore, part-time workers are less available than full-time workers for work-related activities, further education, retraining programs, or other experiences that may contribute to promotion and wage growth (Coverman, 1983). Part-time workers are also typically relegated to low-skilled jobs with low pay (Waldfogel, 1997). Second, individuals may seek jobs that have flexible hours, a location near home, and limited out-of-town travel in order to integrate housework responsibilities with paid work more effectively (Becker, 1991; Coverman, 1983; Hersch, 1991b). The theory of compensating differentials predicts that jobs with these qualities will pay less (Filer, 1985). Third, independent of human capital characteristics, household responsibilities may have a negative effect on wages by limiting the energy and effort available for labor market work and may thereby reduce one's productivity and earnings (Becker, 1985; Hersch, 1985). The assumption here is that individual effort is finite and must be parceled out across all activities. Thus, the amount of effort available for market work is directly diminished by effort expended on housework. Because work effort and wages are likely to be positively correlated, more burdened workers will have less energy and effort available for market work and thus will earn less than those without substantial housework responsibilities. Fourth, employers may also be less likely to hire or promote individuals whom they believe to have substantial housework responsibilities because they expect such individuals to be less reliable workers or more likely to quit (Coverman, 1983; Phelps, 1972). The third and fourth causal pathways are typically identified as "direct," because most research lacks measures of effort and discrimination.

Controlling for measures of human capital, recent studies have empirically tested the direct effect of housework on wages for married men and women. These results suggest that women incur a greater wage penalty than men for time spent on housework (Baxter, 1992; Coverman, 1983; Hersch, 1985, 1991a, 1991b; Hersch \& Stratton, 1997; McAllister, 1990; Shelton \& Firestone, 1988a). This raises a significant question: Why does time spent on housework affect women's earnings more than men's?

The answer may lie in the type of housework that men and women typically do. Housework has two conceptually and analytically distinct dimensions: number of hours and type of tasks (Blair \& Lichter, 1991; Schooler, Miller, Miller, \& Richtand, 1984; Twiggs, McQuillan, \& Ferree, 1999). Other studies of housework, both those predicting time spent in housework (Blair \& Lichter, 1991; Gupta, 1999; Shelton, 1990; South \& Spitze, 1994; Twiggs et al., 1999) and those examining the impact of housework on perceived fairness 
and satisfaction with division of labor (Benin \& Agostinelli, 1988; Blair \& Johnson, 1992) have incorporated this distinction. However, the distinction between types of tasks has been untapped in research examining the effect of housework on wages. Though some have speculated that the differential effects of housework time on wages could be due to the type of tasks performed (Hersch, 1991a, 1991b), no past research has explicitly tested this possibility.

Indeed, numerous studies show that men and women perform very different types of housework (Berk, 1985; Blair \& Lichter, 1991; Coltrane, 1996; Hochschild, 1989). Women traditionally perform chores that take place inside the home and that are closely associated with child care. These types of tasks are generally termed "female" in the literature-because women have more often performed them-and I follow this convention here. Women are usually more involved than men in getting children ready for school in the morning, preparing the evening meal, cleaning the home, and doing laundry (Berk, 1985; Thompson \& Walker, 1989). Importantly, these tasks need to be performed regularly and offer little discretion as to when they are performed, often in close conjunction with the typical workday (Meissner, 1977; Shaw, 1988).

Because of the inflexible and daily nature of female tasks, there are several ways that performing these tasks could negatively affect wages. To begin, female tasks could affect the number of hours available to work in the labor market because these tasks must be performed daily, not just on weekends. Also, because female tasks need to be performed at very specific times, individuals who perform these tasks may be less able to arrive at work early or stay late for special training meetings or other work-related activities (Baxter, 1992). Thus, being responsible for these tasks may act as a barrier to the accumulation of experience and seniority at work. Because these tasks need to be performed daily and at specific times, responsibility for female tasks might also restrict one to flexible jobs, located near home and requiring little out-of-town travel. Furthermore, if there is indeed any reduction in energy and effort available for market work associated with home responsibilities, it is likely to be strongest when performing female tasks, because these tasks usually take place very close in time to market work (Hersch, 1991b).

Men, on the other hand, traditionally perform chores that take place outside the home and do not revolve around daily child care. Traditional "male" tasks, such as household repairs and automobile maintenance, tend to have a well-defined beginning and end, allow discretion as to when the task should be performed, and even include a leisure component (Meissner, 1977). Moreover, male tasks are usually performed on the weekends, distant from market work (Shaw, 1988). The discretionary and infrequent nature of male tasks permits more flexible scheduling around paid work (Shelton \& Firestone, 1988b).

The flexible and infrequent nature of male tasks means that such tasks are not likely to negatively affect wages. For instance, because male tasks are often accomplished on the weekends, performing them is not likely to reduce the number of hours one can work at a 9-to-5 job or to hamper participation in overtime or training programs at work. Also, because male tasks are performed irregularly and distant from market work, responsibility for them is unlikely to restrict one to jobs that have flexible work hours and are close to home (Baxter, 1992). Finally, any reduction in effort caused by housework is unlikely to have a pronounced effect on productivity if housework is not timed closely with market work, as is the case with male tasks (Hersch, 1991b).

Overall, because female tasks need to be performed more frequently and are more inflexible than male tasks, time spent in female tasks is expected to have a stronger negative effect on wages than time spent in male tasks. Moreover, if female tasks have a stronger negative effect on wages than male tasks, segregation of tasks in the home may help explain previous findings that total time spent in housework negatively affects women's wages more than men's wages. That is, it might simply be that men and women are still performing different types of household tasks, and it is female tasks especially that affect wages. In short, disaggregating housework into task types may "explain away" the gender difference in the effect of housework.

\section{METHOD}

\section{Data}

The data come from Wave 1 (1987-1988) and Wave 2 (1992-1994) of the National Survey of Families and Households (NSFH). The NSFH is a national probability sample of 13,007 adults. From the original sample, 10,008 respondents were successfully reinterviewed during Wave 2 . 
The NSFH data are appropriate for this investigation because they include detailed questions on housework as well as data on respondents' income and employment history. Unlike other data sets, the NSFH separates the total amount of time spent on housework into nine different types of chores, allowing me to construct task types. Additionally, these data allow me to use more complete measures of work history than those used in prior studies of the effect of housework on wages. I am able to distinguish between full-time and part-time experience, as well as to identify the number of times a worker exits the labor market. Finally, because the NSFH is a longitudinal panel data set, fixed-effects regression models (to be discussed later) that control for unobserved heterogeneity can be estimated.

I used several criteria to define my sample. First, the sample includes respondents who were interviewed at both waves. This restriction is necessary because fixed-effects models require at least two observations on each person. Second, the sample is limited to working individuals so as to examine the impact of housework on wages. Third, I focus only on continuously married respondents to situate the link between work in and outside the home within the context of marriage. Married respondents are also the focus of most other studies (Baxter, 1992; Coverman, 1983; Hersch, 1985; Hersch \& Stratton, 1997; McAllister, 1990). The data are arranged in a pooled timeseries cross-section with person-years as the unit of analysis. Because there are two waves of data, each respondent contributes two person-year records. The final analytic sample contains 3,384 person-years for 1,692 individuals, consisting of 1,590 person-years for 795 women and 1,794 person-years for 897 men.

\section{Measures}

The dependent variable is the natural log of current hourly wage in the respondent's main job. Using the natural log of hourly wage helps adjust for its skewed distribution. Log-wage also better reflects the nonlinear relationship between the independent variables and wages. For those individuals not paid by the hour (i.e., weekly, biweekly, monthly, or yearly), I calculated the hourly wage by dividing the payment amount by the number of hours the respondent usually works per week and, for those who are paid yearly, by the appropriate number of weeks worked in the last calendar year. Cases that are missing hourly wage and outliers with hourly wages below $\$ 1.00$ and above $\$ 250.00$ are dropped from the analyses.

The primary independent variable of interest is the time spent on different types of housework. The housework data come from answers to a selfadministered questionnaire that asks the respondent to approximate the number of hours spent on nine household tasks during the week preceding the survey. These nine tasks are preparing meals, washing dishes, cleaning house, doing outdoor chores, shopping, washing clothes and ironing, paying bills, maintaining the automobile, and driving. From these nine questionnaire items, I created three separate categories of household tasks and a variable equaling the total amount of time spent in each one. These categories are suggested by theory and are empirically supported through factor analysis; they are also consistent with many other housework analyses, including those by Presser (1994) and Shelton (1992). Tasks that have been traditionally done by women are denoted here as "female" tasks: preparing meals, washing dishes, cleaning house, and washing clothes. Likewise, tasks that have traditionally been done by men are denoted as "male" tasks: outdoor and other household maintenance and automobile maintenance. Finally, tasks that have been traditionally shared equally between men and women are denoted as "neutral" tasks: shopping, paying bills, and driving other household members. In order to provide a reference point to previous work, a variable equal to the total hours spent on housework is also created.

Following a technique used by South and Spitze (1994), two adjustments are made to the measures of time spent on specific tasks. First, because a few respondents reported spending an inordinate number of hours on specific tasks, values above the 99th percentile are recoded to the value at 99\%. The 99th percentile figures range from 10 hours per week on "shopping" to 30 hours per week on "cleaning house". This adjustment reduces skewness in the individual measures and therefore in the summed measures as well. Second, I exclude respondents who did not answer more than two of the nine household task questions. For those who answer at least seven of the nine items, I impute a value of 0 for those who did not answer the question or said the task was inapplicable. For those who spent some unspecified amount of time on the task or stated that they didn't know, I impute the mean value for the task separately for men and women. For each individual for each task, I create two sets of dummy var- 
iables: The first is equal to 1 if that task was imputed with a 0 , and the second is equal to 1 if that task was imputed with the mean. These two sets of dummy variables are included in all the regression analyses; this procedure allows for an adjustment on selectivity as to who neglects to report housework time. Alternatively, I excluded those respondents who did not answer one or more of the nine questions, treated all nonnumeric answers as 0 , and substituted all nonnumeric responses with the mean. The regression results from these alternative approaches did not differ significantly from the results of the chosen approach.

Because I am interested in estimating the direct effect of housework on wages, I control for additional wage predictors that are associated with variation in housework time. I include measures of years of education and years of work experience; both are expected to be associated with higher wages. I distinguish between part-time and full-time years of work experience, because the return to part-time experience is expected to be smaller than that to full-time experience (Corcoran, Duncan, \& Ponza, 1984). Also, I include a measure that captures discontinuities in labor force participation: number of breaks in employment, where a break is defined as a period of 2 months or longer when a respondent is not employed. Employment breaks are expected to have a negative effect on hourly wages (Mincer \& Polachek, 1974). Furthermore, I control for a number of characteristics of the respondent's main job. I include a dummy variable equal to 1 if a respondent is employed in an upper-white-collar occupation (defined as managerial-professional), 0 otherwise. Being in an upper-white-collar occupation is expected to be positively related to wages. A dummy variable equal to 1 for respondents currently working part-time-defined as less than 35 hours per week-is also included. Part-time status is expected to have a negative effect on wages. Two measures that characterize the demands of one's job are included: number of minutes spent commuting to job and an indicator of whether the job requires travel or overnight absence from home. Economic theory predicts that employers will have to pay higher wages to get employees to commute long distances and travel overnight. The total number of children ever born to or adopted by the respondent is included in the model. Number of children is expected to have a positive effect on men's hourly wages and a negative effect on women's hourly wages because of the difference in the level of responsibility assumed for children (Hochschild, 1989). The positive effect of children on men's wages is usually attributed to the greater pressure placed on them to fulfill the breadwinner role.

The data are limited in some respects. Ideally, I would like to control for tenure at current job; however, in the NSFH, the histories of employment do not capture the sequence of jobs that an individual has held, nor do they differentiate among employing organizations. I am also unable to control for labor union membership because the NSFH does not ask respondents such information. Finally, the measure of housework time used here includes only time spent on tasks (e.g., going shopping); it does not include the behind-thescenes responsibility for household management (e.g., making a shopping list) (Mederer, 1993).

\section{Analysis}

Fixed-effects regression models are estimated to assess the direct effects of time spent on various task types on hourly wages. The data are arranged in a pooled time-series cross-section with personyears as the unit of analysis. Effects are fixed for years (period) and persons. The model is as follows:

$$
\ln Y_{i t}=b_{0}+\sum b_{k} X_{k i t}+e_{i t}
$$

where

$$
e_{i t}=u_{i}+v_{t}+w_{i t}
$$

Regression coefficients are denoted by $b, ;$ indexes independent variables; $i$ indexes respondents; and $t$ indexes survey years. The dependent variable, $Y$, is the hourly wage. Because period effects on wages are controlled, it is not necessary to change wages to constant dollars. $X$ is a vector of measurable characteristics expected to affect wages, including housework. Random error terms are represented by $e ; u$ is a time-invariant or fixed individual component of error; $v$ is a time-wise component of error; and $w$ is a classical random normally distributed error component. The coefficients can be obtained by estimating a standard regression model using ordinary least squares (OLS), where a separate dummy variable has been included for each individual and each year (with appropriate omitted categories). I estimate this model using the PROC TSCSREG procedure in SAS (SAS Institute Inc., 1999). Also, because the use of a multistage sampling design could bias the standard errors of estimates, the analyses rely on 
Table 1. Descriptive Statistics for Married Men and Women

\begin{tabular}{lrrrr}
\hline & \multicolumn{2}{c}{ Women } & \multicolumn{2}{c}{ Men } \\
\cline { 2 - 5 } Variable & \multicolumn{1}{c}{$M$} & $S D$ & $S D$ \\
\hline Hourly wage (in dollars) & 11.55 & 8.66 & $17.56^{*}$ & 18.49 \\
Total hours of housework per week & 33.15 & 19.06 & $18.62^{*}$ & 14.28 \\
Total hours of female tasks per week & 25.05 & 14.71 & $7.32^{*}$ & 8.12 \\
Total hours of male tasks per week & 1.97 & 3.14 & $7.10^{*}$ & 6.69 \\
Total hours of neutral tasks per week & 6.13 & 4.70 & $4.20^{*}$ & 4.47 \\
Years of education & 13.63 & 2.45 & $13.98^{*}$ & 3.21 \\
Years of full-time work experience & 13.56 & 9.29 & $20.76^{*}$ & 11.37 \\
Years of part-time work experience & 3.18 & 5.62 & $0.50^{*}$ & 3.09 \\
Number of employment breaks & 1.06 & 1.05 & $0.39^{*}$ & 0.87 \\
Occupation (1 = upper-white-collar) & 0.39 & 0.48 & 0.39 & 0.54 \\
Part-time work status (1 = yes) & 0.29 & 0.45 & $0.04^{*}$ & 0.23 \\
Commuting time (in minutes) & 16.92 & 13.47 & $21.68^{*}$ & 17.65 \\
Travel requirements (1 = yes) & 0.17 & 0.37 & $0.36^{*}$ & 0.54 \\
Number of children & 2.11 & 1.26 & $2.24^{*}$ & 1.66 \\
Age (in years) & 41.29 & 9.59 & 41.69 & 10.91 \\
Race (1 = White) & 0.89 & 0.31 & 0.88 & 0.36 \\
$n$ (person-year) & 1,590 & & 1,794 & \\
\hline
\end{tabular}

Note: These data are weighted.

*Differences in means for women and men are statistically significant at $p<.05$ (two-tailed $t$ tests).

regressions with standard errors adjusted for complex surveys (SAS Institute Inc., 2000).

The fixed-effects specification controls for all unobserved individual characteristics that do not vary over time, because the effects of constant individual characteristics (e.g., race, birth cohort) are absorbed into $u$. In this way, fixed factors related to wages are cancelled out of the earnings equation. Only measures of individual characteristics that change over time are included in these models.

The ability of fixed-effects techniques to control for characteristics that are invariant for an individual across time is particularly important in models of the impact of housework on wages, because a variety of unmeasured individual characteristics, such as motivation, ambition, or ability, are likely to affect both time spent in housework and wages. For example, if individuals with lower motivation to succeed in the labor market are more likely to spend time on housework and less likely to have high earnings, then this unobserved heterogeneity might explain the earlier findings that housework time has negative effects on earnings. The concern here is not with reverse causality (to be discussed later); rather, it is that some unobserved factor is affecting both housework time and wages. My analysis controls for these unmeasured individual characteristics, so long as their effects do not change over time.

Fixed-effects models also have the benefit of removing systematic biases that may exist in mea- sures of housework time. For example, Juster and Stafford (1991) find that retrospective data, like the NSFH, systematically overestimate measures of household labor time compared to time diary data. Assuming that individuals consistently overestimate their housework time over time, fixedeffects estimation will correct for this, and the analyses will not be influenced by this bias.

Separate regression models are estimated for men and women. In order to provide a basis for comparison to previous work, a model that includes a variable measuring the total hours spent on housework on wages is first estimated. Next, I estimate a model that categorizes housework into different task types. Finally, I perform sensitivity analyses to check an alternative categorization of task types and nonlinearity in the houseworkwage model.

\section{RESULTS}

\section{Descriptive Statistics}

Table 1 provides descriptive statistics for the measures included in the analyses for both men and women. As expected, there are substantial and statistically significant sex differences in most of the variables. On average, women earn $\$ 11.55$ per hour, whereas men earn $\$ 17.56$ per hour. As these data indicate, comparisons of total hours devoted to housework reveal very large sex differences. Women perform on average more than one and a 
half times the amount of housework as men perform, 33 hours versus 19 hours, respectively. Not surprisingly, housework tasks are also highly segregated by sex. Women spend considerably more time in female tasks than do men, 25 hours versus 7 hours. Men, on the other hand, spend considerably more time in male tasks than do women, 7 hours versus 2 hours. Women spend slightly more time than men in neutral tasks, 6 hours versus 4 hours. It should be noted that the female-male task-type theoretical distinctions stem from relative contributions of husbands and wives to given tasks, not from comparisons of an individual's time across tasks. The results from these data (not shown) reveal that, on average, wives perform $77 \%$ of the female tasks and only $23 \%$ of male tasks within the married couple. On the other hand, husbands perform on average $78 \%$ of the male tasks and only $24 \%$ of female tasks.

With respect to the control variables, men have slightly more education than women, 14.0 years versus 13.6 years. Women have about 7 years less full-time work experience than men, but about 2.5 years more part-time work experience. On average, women have taken more employment breaks than men and are more likely to be currently working part-time. About $40 \%$ of women and men are in upper-white-collar professions. Women's commuting time is also about 5 minutes less than men's, and women are less likely than men to have jobs that require extensive travel. Men in the sample have slightly more children than women. The values of remaining demographic controls (age and race) are equal for women and men.

\section{Regression Results}

Table 2 shows results for the fixed-effects models. Race drops out of the analysis because it is fixed over time. Age is also not included in the models. This is because age is implicitly controlled, because both period and cohort (via the person-specific fixed effect) are controlled: Period and cohort together uniquely determine age. Because wages are in logarithmic form, coefficients multiplied by 100 are interpreted as the percentage change in hourly wages that would result from a unit increase in the independent variable. Model 1 estimates the direct effect of total hours of housework per week on hourly wage of men and women.

Consistent with other work (Baxter, 1992; Coverman, 1983; Hersch, 1985, 1991a, 1991b; Hersch \& Stratton, 1997; McAllister, 1990; Shelton \& Firestone, 1988a, 1988b), an increase in time spent in housework is negatively related to wages, and this is stronger for women. A 1-hour increase in housework decreases women's hourly wage by $0.3 \%$. Housework does not have a significant effect on wages for men, and the effect of housework on wages is significantly different by gender. This finding of significant gender differences provides the impetus for breaking housework down into task types. Doing so will enable me to determine whether the gender difference in effect is due to men and women performing different types of chores.

The other independent variables in the analysis operate as expected. Hourly wage increases with being in an upper-white-collar profession for women. For men, wages increase with full-time work experience. Whereas employment breaks and part-time status have a negative effect on men's wages, commuting time and travel requirements are associated with higher hourly wages for men. Hourly wage also increases with number of children for men.

Model 2 estimates the effect of time spent in female, male, and neutral tasks on hourly wage. For women, the results show that only time spent in female housework chores has a significant negative effect on wages. A 1-hour increase in female housework decreases women's hourly wage by $0.5 \%$. The effect of male and neutral tasks is positive for women, though not statistically significant. For men, female housework is also the only task type that has a significant negative effect on wages. A 1-hour increase in female housework decreases men's hourly wage by $0.4 \%$. The effect of male and neutral tasks on wages is positive for men, although not statistically significant. The effect of female, male, and neutral tasks on wages does not differ significantly by gender.

\section{Sensitivity Analysis}

Instead of categorizing the tasks as female, male, and neutral, I could have categorized tasks as inflexible-frequent (preparing meals, washing dishes, cleaning house, washing clothes, shopping, and driving other household members) and flexible-infrequent (outdoor and other household maintenance, automobile maintenance, and paying bills). The theoretical argument would be similar to the one presented above. That is, a potential explanation for the gender difference in the effect of total housework time on wages is that women spend more time than men performing inflexiblefrequent tasks, and men spend more time than 


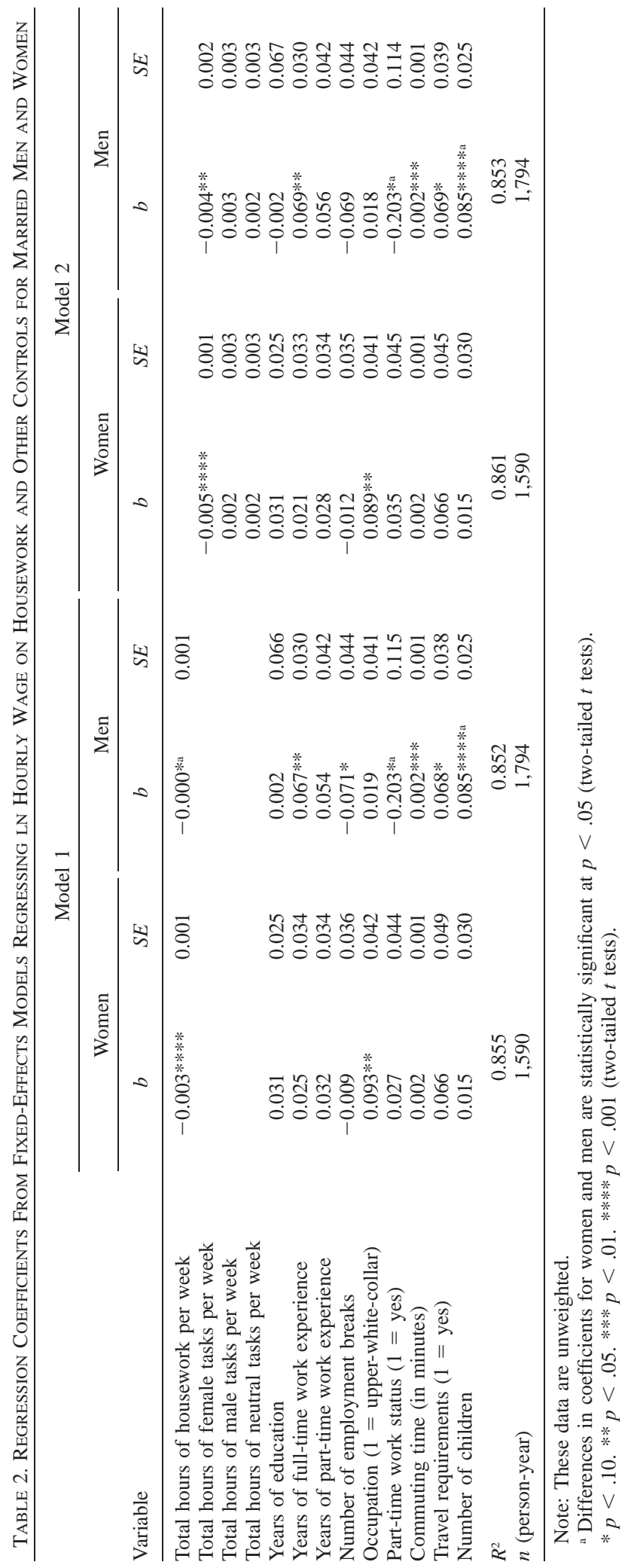


women performing flexible-infrequent tasks. The results from this categorization of task types do not differ substantively from those presented here (not shown). The effect of inflexible-frequent tasks on wages is negative and statistically significant for both men and women. The effect of flexible-infrequent tasks on wages is positive and not statistically significant for both men and women. The effect of these task types on wages does not differ significantly by gender.

I also explored whether the relationship between housework and wages is nonlinear. To account for possible nonlinearity associated with housework in the model, a squared term for time spent in each task type was added to Model 2. The housework-squared terms were not significantly related to wages for either men or women.

\section{Endogeneity}

The causal model in this article posits housework time as an exogenous variable and wages as the endogenous outcome of variation in housework time. This model assumes that wages do not affect housework time and that all the association between housework and wages is entirely the effect of housework. However, it is plausible that the causal relationship between housework and wages also exists the other way around. That is, causation may be running in both directions (Baxter, 1992; Coverman, 1983; Hersch, 1991a; Hersch \& Stratton, 1997; Shelton \& Firestone, 1988a). This problem is inherent in many studies of the relationship between work and family.

Wages may affect time spent in housework in two ways. Higher wages may enable an individual to "buy" out of household work by making market substitutes (e.g., maids, restaurants, laundry services, prepackaged and convenience foods) more affordable (Becker, 1991; Hersch, 1991a; Hersch \& Stratton, 1997; Oropesa, 1993). Also, higher wages may enable one to demand greater spousal participation in housework in place of one's own housework time (Maret \& Finlay, 1984).

If the arguments regarding the endogeneity of housework are correct, then OLS estimates of housework will be downward biased; that is, housework will appear to have a greater negative impact on wages than it actually does. One common statistical technique to help account for the problem of endogeneity is instrumental variables (IV) estimation. The instrumental variables are assumed to be correlated with the potentially en- dogenous variable (housework time) but to have no direct association with the outcome (hourly wage). Identifying appropriate instrumental variables that are correlated with housework time but not directly correlated with hourly wage is exceedingly difficult given the limited choices in this data set. I explored five potential instrumental variables (home ownership, other family income, gender role attitudes, housework performed by others in the household, and spouse's work status), but none fulfilled this key IV assumption. Because of this, I don't pursue IV estimates. Other research has shown that IV techniques provide notoriously poor estimates when inadequate instruments are used (Bound, Jaeger, \& Baker, 1995; Kmenta, 1971).

Uncertainty about the true causal model does not invalidate the results of this analysis, although it should be kept in mind when interpreting the results. Better clarifying the complex relationship between housework and wages requires frequent panel data at several time points so that the temporality between housework and labor market events can be precisely laid out. The NSFH data, so far including two time points separated by roughly 5 years, are the best data available at this time.

\section{DisCUSSION}

Feminist research has long argued that the spheres of home and work are integrally related. In this article, I examine one of the linkages between home and work by empirically testing the relationship between time spent in various types of housework and wages of married men and women. The results support the hypothesis that time spent in female tasks, which are the most inflexible and performed the most regularly, has a larger negative impact on both men's and women's hourly wage than time spent in male or neutral tasks. In fact, I find that only time spent in female housework chores has a negative effect on hourly wage. This negative effect is "hidden" for men when using a total housework variable, because a smaller proportion of their total housework time is composed of female tasks. Furthermore, categorizing housework into various task types offers a link to the puzzling result that total hours of housework has a stronger effect on women's wages than men's wages. Disaggregating housework into task types, there are no gender differences in the effect of housework on wages.

The fact that these female housework penalties 
exist in fixed-effects models is evidence that the effect of female housework is not due to unobserved heterogeneity. Furthermore, these findings are quite conservative, because they capture only the direct effect, not total effect (direct plus indirect), of housework time on wages. Even after controlling for a host of human capital characteristics and controls, the negative effect of female housework on wages persists. One possible mechanism through which female housework may be affecting wages is through reducing energy and effort available for market work. Alternatively, or additionally, employers may be discriminating against those who perform female housework in a way that affects wages. These findings may also be conservative because of the measure of housework used in the analysis. For instance, Mederer (1993) has argued for a comprehensive measure of household labor, one that includes not only time spent accomplishing specific tasks, but also responsibility for household management. If management of female tasks affects wages in a way similar to time spent accomplishing female tasks, it may be that the results presented here are underestimates of the true effect of housework on wages.

These findings should, however, be interpreted with caution because of potential nonrecursivity between housework time and wages in the models. The lack of appropriate instrumental variables precludes an unequivocal assessment of this endogeneity. Panel data at frequent time points would also be useful in sorting out the causal relationships between housework and wages.

Housework consumes a substantial amount of time, and these results suggest that decisions regarding the division of housework time and task types have important implications for life outside the home. Indeed, there are hidden costs to performing female housework tasks. It is likely that the wage penalty from performing female chores is contributing to the overall gender gap in pay, because women spend considerably more time in female housework than men do. There are no comparable wage penalties for performing male tasks. Although many men who perform traditionally male tasks escape the negative effect of housework, the gendered allocation of housework depresses earnings of women, reinforcing economic dependence and traditional gender roles (Hartmann, 1976).

These findings imply that gender equality in the labor market depends partly on a more equitable distribution between the sexes of not only the amount, but also the type, of work performed in the home. Public policy and the media can inform the public that a more equitable distribution of both amount and type of housework is an important factor in reducing the male-female earnings gap. At the structural level, employers can make work more accommodating for individuals with inflexible, routine female household responsibilities. Most wage work in our society facilitates a reward structure that promotes continuous employment and long and inflexible hours. This structure is inconsistent with female housework responsibilities. As the spheres of work and home become more intertwined, employers are increasingly pressured to make the workplace friendlier to the family roles of both men and women. By offering flexible working hours, telecommuting, and job sharing, employers can better attract and hold onto employees with household responsibilities that interfere with work. For example, alternative work schedules allow workers to perform female tasks without sacrificing investments in their work life. Finally, employers can expand services such as in-house dry cleaning, personal shopping, and the preparation of take-home evening meals to help diminish the conflict between family and work.

These findings emphasize the importance of integrating domestic work with market work when attempting to explain the labor force experience of men and women. Future research should continue to explore the impact that the domestic sphere may have on the labor market, with attention to the type of housework performed. The inclusion of task types is essential, both in validly measuring housework and in broadening our understanding of how housework affects labor market outcomes. Also, researchers should continue to work to illuminate the mechanisms by which housework limits success in the labor market. This may be accomplished by exploring the impact of housework on wages for different subgroups, defined by such variables as race, age, marital status, occupation, part-time/full-time employment status, and type of employment schedule (e.g., shift worker vs. traditional 9-to-5 worker). Understanding the impact of housework on labor market outcomes will only become more important with the increase in dual-earner couples juggling both work and family roles.

\section{Note}

An earlier version of this article was presented at the annual meeting of the Population Association of Amer- 
ica in New York City, 1999. I thank Pamela Smock, Sanjiv Gupta, Yu Xie, Brent Berry, and Jennifer Barber for their helpful comments. I also thank Michelle Budig and Paula England for their valuable suggestions. This research was supported by an NICHD traineeship (2 T32 HD07339).

\section{REFERENCES}

Baxter, J. (1992). Domestic labour and income inequality. Work, Employment, and Society, 6, 229-249.

Becker, G. S. (1985). Human capital, effort, and the sexual division of labor. Journal of Labor Economics, 3, S33-S58.

Becker, G. S. (1991). A treatise on the family. Cambridge, MA: Harvard University Press.

Benin, M. H., \& Agostinelli, J. (1988). Husbands' and wives' satisfaction with the division of labor. Journal of Marriage and the Family, 50, 349-361.

Berk, S. F. (1985). The gender factory: The apportionment of work in American households. New York: Plenum Press.

Blair, S. L., \& Johnson M. P. (1992). Wives' perception of the fairness of the division of household labor: The intersection of housework and ideology. Journal of Marriage and the Family, 52, 570-581.

Blair, S. L., \& Lichter, D. T. (1991). Measuring the division of household labor: Gender segregation of housework among American couples. Journal of Family Issues, 12, 91-113.

Bound, J., Jaeger, D. A., \& Baker, R. M. (1995). Problems with instrumental variables estimation when the correlation between the instruments and the endogenous explanatory variable is weak. Journal of the American Statistical Association, 90, 443-450.

Coltrane, S. (1996). Family man: Fatherhood, housework, and gender equity. New York: Oxford University Press.

Corcoran, M., Duncan, G., \& Ponza, M. (1984). Work experience, job segregation, and wages. In B. Reskin (Ed.), Sex segregation in the workplace: Trends, explanations, remedies (pp. 171-191). Washington, DC: National Academy Press.

Coverman, S. (1983). Gender, domestic labor time, and wage inequality. American Sociological Review, 48, 623-637.

Coverman, S., \& Sheley, J. F. (1986). Change in men's housework and child-care time: 1965-1975. Journal of Marriage and the Family, 48, 413-422.

Filer, R. K. (1985). Male-female wage differentials: The importance of compensating differentials. Industrial and Labor Relations Review, 38, 426-437.

Gupta, S. (1999). The effects of transitions in marital status on men's performance of housework. Journal of Marriage and the Family, 61, 700-711.

Hartmann, H. (1976). Capitalism, patriarchy, and job segregation by sex. Signs, 1, 137-169.

Hersch, J. (1985). The effect of housework on earnings of husbands and wives: Evidence from full-time piece rate workers. Social Science Quarterly, 66, 210-217.

Hersch, J. (1991a). The impact of non-market work on market wages. The American Economic Review, 81, $157-160$.

Hersch, J. (1991b). Male-female differences in hourly wages: The role of human capital, working condi- tions, and housework. Industrial and Labor Relations Review, 44, 746-759.

Hersch, J., \& Stratton, L. S. (1997). Housework, fixed effects, and wages of married workers. The Journal of Human Resources, 32, 285-307.

Hochschild, A., (with Machung, A.). (1989). The second shift. New York: Viking.

Juster, F. T., \& Stafford, F. P. (1991). The allocation of time: Empirical findings, behavioral models, and problems of measurement. Journal of Economic Literature, 29, 471-522.

Kamo, Y. (1988). Determinants of household division of labor: Resources, power, and ideology. Journal of Family Issues, 9, 177-200.

Kmenta, J. (1971). Elements of econometrics. New York: Macmillan.

Maret, E., \& Finlay, B. (1984). The distribution of household labor among women in dual-earner families. Journal of Marriage and the Family, 46, 357364.

McAllister, I. (1990). Gender and the household division of labor. Work and Occupations, 17, 179-199.

Mederer, H. J. (1993). Division of labor in two earner homes: Task accomplishment versus household management as critical variables in perceptions about family work. Journal of Marriage and the Family, 55, 133-145.

Meissner, M. (1977). Sexual division of labor and inequality: Labor and leisure. In M. Stevenson (Ed.), Women in Canada (pp. 160-180). Toronto, Canada: Women's Educational Press.

Mincer, J., \& Polachek, S. (1974). Family investments in human capital: Earnings of women. Journal of Political Economy, 82 (2), S76-S108.

Oropesa, R. S. (1993). Using the service economy to relieve the double burden: Female labor force participation and service purchases. Journal of Family Issues, 14, 438-473.

Phelps, E. S. (1972). The statistical theory of racism and sexism. American Economic Review, 62, 659661.

Presser, H. B. (1994). Employment schedules among dual-earner spouses and the division of household labor by gender. American Sociological Review, 59, 348-364.

SAS Institute Inc. (1999). SAS/ETS user's guide, Version 7.1. Cary, NC: Author.

SAS Institute Inc. (2000). SAS/STAT user's guide, Version 8. Cary, NC: Author.

Schooler, C., Miller, J., Miller, K. A., \& Richtand, C. N. (1984). Work for the household: Its nature and consequences for husbands and wives. American Journal of Sociology, 90, 97-124.

Shaw, S. M. (1988). Gender differences in the definition and perception of household labor. Family Relations, 37, 333-337.

Shelton, B. A. (1990). The distribution of household tasks: Does wife's employment status make a difference? Journal of Family Issues, 11, 115-135.

Shelton, B. A. (1992). Women, men and time. New York: Greenwood Press.

Shelton, B. A., \& Firestone, J. (1988a). An examination of household labor time as a factor in composition and treatment effects on the male-female wage gap. Sociological Focus, 21, 265-278.

Shelton, B. A., \& Firestone, J. (1988b). Time constraints 
on men and women: Linking household labor to paid labor. Sociology and Social Research, 72 (2), 102-105.

South, S. J., \& Spitze, G. (1994). Housework in marital and non-marital households. American Sociological Review, 59, 327-347.

Thompson, L., \& Walker, A. J. (1989). Gender in families: Women and men in marriage, work, and parenthood. Journal of Marriage and the Family, 51, 845-871.
Twiggs, J. E., McQuillan, J., \& Ferree, M. M. (1999). Meaning and measurement: Reconceptualizing measures of the division of household labor. Journal of Marriage and the Family, 61, 712-724.

U.S. Bureau of the Census. (1999). Statistical abstract of the United States. Washington, DC: Author.

Waldfogel, J. (1997). The effect of children on women's wages. American Sociological Review, 62, 209217. 